\title{
Urban Development: The Redistribution of Persistent Deprivation
}

\section{Alan Rew and Richard Batley}

The inadequacy of partial, sectoral analyses of Britain's current development problems is increasingly recognised. The approach of development studies-to the extent that it deals with the total social, political and economic context of any particular sectoral problem-is thus increasingly attractive. Nonetheless, 'Britain as a developing country' ought to be treated as a question, rather than a statement or conclusion. This caution is particularly important where the area of concern is social welfare policy, persistent deprivation and their manifestation in housing location and housing allocation.

The theme is questionable at a number of levels. First, Britain continues to benefit from very high levels of past investment and fixed capital in housing and infrastructure. Visitors from developing countries may be unwilling to extend much sympathy to Britain's 'development' while British public housing standards are unobtainable by even middle-class applicants in their own countries. Second, the welfare state in Britain is well established. Furthermore, British experience in housing has been exported as a model to be followed, or at least closely examined, by .Third World housing sector policy-makers: it is not an independent test-case.

Populist programmes for social and economic change in newly independent African and Asian countries have often put emphasis on the improvement of housing and housing services, particularly in the urban areas. Such popular housing programmes have usually been difficult to implement and have seldom benefited those for whom they usually were intended. Few developing countries can finance extensive building programmes, or find the managerial and artisan skills and administrative machinery to make them possible. House construction is seldom attractive to the private sector because of a low rate of profit compared with hotel or office contruction. Inevitably, few houses have been built, and these have on the whole been allocated to government officials and others with financial means and political connections. Housing has become in the popular imagination a wage-good for administrators and equivalent groups.
Thus the rate of production usually fails to keep pace with population growth and rural-urban migration. Policy-makers are all too aware of the gap between the housing provided in the 'formal' sector and their inability to provide even barely adequate shelter for the urban masses. Yet at the same time it is often argued, especially by those concerned with rural development, that too many resources are already allocated to the cities: the further development of urban services will only speed up rural-urban migration and weaken the ability of the countryside to develop itself.

These problems seem a far cry from British experience. Britain has developed a housing stock which in aggregate seems adequate for its population's needs. Its problems appear rather to be those of market and administrative mis-allocation and labour immobility. Yet concern about the possible implications of housing for migration and labour mobility is usually secondary to its acceptance as an essential provision of the welfare state. There is considerable variety at the local level because of local political differences and pressures, but on balance housing is normally delivered on the basis of administratively-defined social need rather than as an instrument of regional policy and employment balance.

A comparision of the British and Third World experience nevertheless has valuatle lessons to offer for both. This is particularly evident in the making and implementation of policy related to metropolitan growth. In many countries, including the United States and much of the Third World, megapolitan growth and concentration seem relentless. Symposia are devoted to 'the exploding cities'; and end of the century projections for cities like Calcutta, Manila, Mexico City and Sao Paulo reckon populations in tens of millions. There is, therefore, considerable interest in the developing countries in efforts to decongest large metropolitan centres such as London. The Philippines, for example, has consciously based some of its policies on British new towns; subregional growth centres have been established in central Luzon and the establishment of new, polluting industries within $50 \mathrm{~km}$ of the centre of Manila has been banned in an attempt to slow down metropolitan growth. 
The lessons, however, are not always positive. Close examination of the British experience of decongesting cities suggests that while the policy has been implemented successfully in terms of its original aims, equally formidable new problems have been created. Moreover, Britain's faith in the neutrality and efficiency of its public service has made it difficult to spot difficulties which would be self-evident in developing countries, where social service ideologies would be less likely to obscure the contradictions between welfare and production and employment, the operation of class alignments and the dilemmas of state intervention in urban development.

The post-war programme for 'decongesting' London's population and industry was wholly successful in its own terms. Between 1961 and 1974 the population of Greater London fell by 803,000 and over the same period the capital's manufacturing employment declined by one third. The promotion of new and expanding towns was one expression of this policy and, again, much can also be claimed in terms of their own viability. Industry has been attracted to the new towns to match the expansion of their population; and they have become a profitable state enterprise of which the Treasury is a net beneficiary.

Yet in terms of the changed criteria of regional development policy they are now believed to have been misdirected. The minister of housing who was responsible for London in 1964 now says that he was 'guilty' of taking wrong advice in favour of a decentralisation which actually led to the deterioration of conditions in London (Mellish, 1977). In accordance with this view, the Government has announced cuts in new town population and expenditure targets in order to channel investment back to the metropolitan centres (House of Commons, 1977). The new town policy which was to save the old cities by decongesting them is now to be sacrificed (or at least restrained) for their revival.

The initial success and subsequent over-success of decongestion is one way of analysing the situation. It is doubtful, however, whether it tells us much about the actual outcomes of policy. If one begins on the other hand by scrutinising these outcomes, it is easier to see how inner London boroughs have been caught in a perverse set of relationships and networks centred around the provision of employment and housing.

For it was inner London which benefited (or, with hindsight we might say suffered) most from the reduction in population and the loss of industry. However, the decline in employment and population has had none of the favourable
Population decline in London

\begin{tabular}{llccc} 
& \multicolumn{3}{c}{ fall } & fall \\
$\%$ & 1961 & $\%$ & 1971 & $\%$
\end{tabular}

$\begin{array}{cccccc}\begin{array}{c}\text { Outer } \\ \text { London } \\ \text { Inner }\end{array} & 4,515,255 & 4,499,564 & 0.3 & 4,399,316 & 2.2 \\ \text { London } & 3,681,552 & 3,492,879 & 5.1 & 2,979,698 & 14.7 \\ \text { Source: } & 1971 \text { Census Office of Population and } \\ & \text { Census Statistics }\end{array}$

effects that 'decongestion' was supposed to bring. The people leaving the inner city have been the younger and the more skilled who were selected for housing and jobs in the new and expanding town and suburbs. Meanwhile, the Inner London boroughs' own post-war commitment to a large scale house-building programme, operated on the basis of family need, has reduced the mobility of a population which finds it increasingly difficult to find work in London. While manufacturing has declined, London's administrative and service functions have expanded, but these offer fewer jobs to the semi and unskilled workers who are concentrated in the inner city, most of whom are in relatively unstable and badly paid employment. The growth of this sector of employment has had two other polarising effects. First office and hotel development has contributed to high speculative land prices which have made it more difficult for poorer people to move out of the poorer boroughs. And second it has progressively concentrated the business component of London's tax (rates) base in the core City area.

The fulfillment of public housing obligations commits local authorities to heavy social service expenditures on a relatively needy and immobile population. But office development, extending the City of London's functions into surrounding boroughs, is the only way of expanding employment and gaining revenue in order to finance social services and housing. The dilemma is that this is precisely the development least suited to the population's employment needs. It may even increase the demand for public housing by encouraging the demolition of cheap private rented accommodation as well as by destroying those small businesses which remain. But the alternative of promoting manufacturing employment is scarcely available, not only because costs and incentives have removed it from inner city areas but also because other aspects of decentralisation policy stand in the way. Until the recent policy changes, inner London boroughs have been forbidden by central government from advertising for industrial expansion, and even existing manufacturing companies have found it difficult to obtain government permission (industrial development certificates) to expand. 
The population of central London finds itself trapped in these contradictions: those least suited to the new employment opportunities are most likely to qualify for public housing; those wishing to move are held in the inner city by the untransferability of council house eligibility rights and the financial exclusiveness of the private housing market.

The attempt to reorder priorities in order to bring about the flow of resources from new towns to the inner cities assumes not only that existing policy instruments are broadly correct, although needing redirection, but also that policies are in fact reversible. Major changes do not occur just because new policies are formulated. The firms (and people) that were removed from central city areas by planning policies, costs, and the infrastructural and investment attractions provided in alternative areas, cannot easily be brought back. They may have good reasons for staying where they are with relatively lower costs and improved services. Interests become entrenched as new structures (not least governmental) establish themselves. The dynamism of well-established policies was illustrated, the day before the Government's announcement of its change in priorities, by Crawley New Town's call for further government investment in the town's housing to help satisfy its industries' needs for skilled labour, since the alternative was to continue to import labour daily from London.

Even if we asume that government can in fact successfully reorder its priorities, questions remain about the future flow of investment. In a period of low growth is there in fact any development to share out? Is there any reason to assume that the investment will revert to the old cities in the absence of government compulsion? Policymakers tend to assume that if a formal structure (of local, regional or central government or a new partnership between them) exists to coordinate services and plan economic strategy, then coordination and strategic development happen. The experience of the Greater London Council, established in 1963 as the first metropolitan strategic planning authority, is hardly encouraging. Its planning is ineffective in the absence of executive authority and tends to break down as soon as the separate interests of boroughs are exposed. Its house-building programme has usually been forced back in to inner London by the reluctance of outer suburban boroughs to accept increases in population which might increase their social service obligations and ad-versely affect property values. The possibility of radical and irremovable conflict can seldom be seriously discussed since any 'conflict' is decreed to be about limited 'issues' - such as the transferability of particular, individual eligibilities for public housing - and not about the possible perversities of the system. If the productive structure of British society is not in question then a range of particular blockages may escape notice: the response to continuing deprivation may be an uncritical call for more and better services. If incomes are falling and alternative options receding, government activities are more readily seen to be ineffective, awkward or even perverse. The perversity is precisely that in the real world of housing and employment outcomes, public sector interventions tend to redistribute problems of deprivation and poverty, both geographically and socially: they rarely eradicate them.

Indeed, the admirable and often envied concern with social welfare and distribution in British housing policy may be a weakness. The complex structural patterning of welfare outcomes is obscured by the fact that policy-implementing institutions constantly reiterate a narrow sectoral definition of their function. Moreover in the close relationship between policy and research, prescription and analysis become easily confused.

Social policy research tends to remain caught up in and often dominated by the language and activities of the sponsoring agencies and departments. 'Slum clearance', 'inner city development', 'public health', 'housing', etc. become convenient foci of research, diverting attention from the relationships between the structures of distribution and of production and their impact on the welfare and life-chances of actual households. Even the tradition of local and community study in British social science which has always maintained its own independent perspective on social problems has succumbed to the sectoral approach to the extent that it has concentrated on issues of local community relations and conflict rather than the macro-structural context in which they are determined by policy-makers. The recent interest in Marxist analyses of urban development in Britain is often only a reaction to the limitations of the sectoral approach, rather than being immediately concerned with the language and perspective of the policy-maker and his response to the political-economic context in which he implements policy.

The belief that the problem of 'urban deprivation' is an aberration and soluble by ad hoc interventions is, then, a reflection of the sectoral nature of most British social research and policy-making. Problems are perceived as isolated 'social welfare' phenomena rather than as systemically related 
political-economic relations. This is in spite of the fact that governments have chased the problem full circle and found that every sort of solution seems to do little more than pick up some of the pieces left by the previous one. Policies for the removal of population and industry from major cities give way to policies for their return; programmes for the physical improvement of urban housing provoke the eviction of poorer tenants; improvements in the security of private tenants contribute to the worsening of the housing prospects of the homeless; high rise council housing, a solution 10 years ago, is now a problem for both tenants and housing managers; legislation to acquire for the community the betterment value of land is thwarted by a lack of finance to acquire land and the reluctance of owners to sell.

Yet each failure in welfare and policy terms appears to reinforce the search for solutions which are as contained, sectoral and ad hoc as those they follow. Failure may suggest that new agencies, ministries or departments are noeded; that proper coordination is absent; that new research methodologies could produce the material essential for consistent planning; or that a new kind of administrative expertise is needed. These solutions and adjustments to failure rarely challenge the institutionally acceptable rationale for administrative activity.

Calling for new commitments and a new evangelism among politicians and administrators is scarcely more effective than calling for new departments. The inevitable ambiguities of policy based, for example, on themes of equality of opportunity' are unlikely to be removed by more exacting personal commitments or calls for 'parity of esteem'. Even to emphasise the citizen's political choices or the possibility of client advocacy and participation, is still to look for an administratively convenient solution. When client groups are sponsored by welfare administrations they rapidly lose their authenticity as grass-roots movements. They tend to collapse when the specific issues they are organised to attack are either attained or blocked, or when the administration weakens in its support by removing key liaison officials (Rein, 1969).

All these responses to persistent urban deprivation reflect that welfare monism which frames so much of policy and policy diagnosis. Failures in a programme are either diagnosed wholly within the conventional framework of institutional reform or by creating and thrusting into prominence a weakness such as 'poor coordination' to avoid facing the real contradictions between welfare and production aims which extend over wide areas of policy and activity.

In the face of the inadequacy of its sectoral policies, government has resorted, since 1968, to a ceaseless round of small-scale special projects designed to demonstrate the power of coordinated (that is cross service) action which is never, however, countenaced on a grand scale and which is always applied locally rather than to central government. The research associated with community development projects, inner area studies, the urban aid programme, neighbourhood schemes and comprehensive community programmes has consistently concluded, however, that the problems of the inner cities are neither localised, nor pathological, nor amenable to even the most coordinated treatment by the social services, but are integral to much more fundamental structures of inequality. This is not so much a question of limited policy ambitions as a failure to respond with imagination to the outcomes of policy. Current government statements about the problems of the inner city areas, for example, can hardly be faulted for the breadth of their description:

"The old problem of poor housing-and in some areas, congestion-have still to be overcome, but in many areas they have been joined by new problems of high unemployment, decay and dereliction, unbalanced population structure, with disproportionate numbers of the disadvantaged and the elderly, and an accompanying loss of internal morale and external confidence" (House of Commons, 1977A).

However, except that legislation is promised to "enhance the powers of local authorities-to enable them to assist industry and designate industrial improvement areas", the action that is proposed remains selective, cheap, small-scale and local. 'Partnerships' are to be formed between central government departments and a very few selected local authorities to develop 'coordinated' action (sharing between them a budget of $£ 100 \mathrm{~m}$ ). On past experience, we might question whether such ad hoc groupings are capable of imposing a global view on agencies with separate interests, structures, and orientations.

We must continue to wonder, therefore, if the of ten perverse welfare and employment implications of rural-urban movement and resource extraction and allocation which are so characteristic of Third World countries have been ever seriously considered for their possible implications for Britain. Such processes drain the rural areas of resources and leave behind the needy: are the flows of resources to the new towns and the diffi- 
culties faced by iinner London boroughs so very different? Similarly, if the customary faith in the overall rationality of a welfare bureaucracy's implementation is questioned-as it usually is in developing countries-would this bring into question the current language and ambitions of the policy-maker, and lead to a more creative response to policy failures? A world of known perversities and contradictions is certainly unsettling and tentative. But for developing countries it constitutes the everyday world of urban development policy.

\section{References}

House of Commons, 1977, Announcements by the Secretary of State for the Environment, 5 and 6 April

House of Commons, 1977A, Hansard, 6 April vol. 929, Col. 1227

Mellish, Bob, MP, 1977, Hansard 14 January, vol. 923 cols $1809-1908$

Rein, M., 1969, 'Social Planning: the search for legitimacy', Journal of the American Institute of Planners, vol. 35 